\title{
A categoría da modalidade e a súa expresión na lingua galega
}

\section{The category of modality and its expression in Galician}

\author{
Vítor Míguez \\ Universidade \\ ORCID: 0000-0001-7138-373X \\ vmigreg@cirp.gal
}

Centro Ramón Piñeiro para a Investigación en Humanidades, Consellería de Cultura, Educación e

Recibido: $15 / 01 / 2021$

Aceptado: 22/03/2021

\section{Resumo}

A modalidade é unha categoría de análise de grande éxito na lingüística que recibiu escasa atención nos estudos sobre o galego. Esta contribución mostra as dificultades con que baten os achegamentos lingüísticos tradicionais á hora de alcanzar unha definición coherente da modalidade e defende, a partir do exame da realización interlingüística das categorías modais, que a modalidade tal e como foi entendida tradicionalmente dá cobertura a trazos peculiares das linguas máis estudadas e que estes son escasamente representativos do comportamento xeral das linguas. Como alternativa, proponse un marco de traballo para o tratamento das categorías modais que diverxe do achegamento tradicional, na medida en que parte dunha definición estrita dos dominios conceptuais e dunha perspectiva ampla da súa realización formal. Neste marco, o concepto xeral de modalidade perde protagonismo para deixar paso ás nocións, conceptualmente simples e coherentes, de modalidade deóntica, modalidade epistémica, modalidade inferencial e modalidade afectiva. Estas nocións constitúen dominios semánticos independentes, mais posúen características comparables en termos de estrutura e alcance semánticos. A argumentación acompáńase de exemplos, tirados dun corpus electrónico, representativos da diversidade formal que ofrece o galego para a expresión destas categorías semánticas.

\section{Palabras chave}

semántica, gramática, modalidade, evidencialidade, galego

\section{Sumario}

1. Introdución. 2. A(s) modalidade(s): da lóxica á lingüística. 2.1. As clases tradicionais de modalidade. 2.2. Outras propostas de organización da modalidade. 2.2.1. Modalidades dinámica e deóntica alén do tradicional. 2.2.2 Divisións alternativas do espazo modal. 2.3. A(s) definición(s) da modalidade. 3. A modalidade desde a perspectiva tipolóxica. 4. Modalidades sen modalidade: un marco de traballo alternativo. 5. A expresión das modalidades na lingua galega. 6. Conclusión.

\section{Abstract}

Modality is a very successful analytical category in linguistics but has received little attention in studies on Galician. This contribution shows the difficulties that traditional approaches to modality face when trying to develop a coherent definition of modality. Drawing on the examination of the crosslinguistic realization of modal categories, it is argued that modality, as it has been traditionally understood, covers features specific to the most studied languages that are hardly representative of the general behavior of linguistic diversity. As an alternative, a framework is proposed for the treatment of modal categories that diverges from the traditional approach, insofar as it starts from a narrow definition of conceptual domains and takes on a broad perspective on their formal realization. In this framework, the general concept of modality is sidelined in favor of the conceptually simple and coherent notions of deontic modality, epistemic modality, inferential modality and affective modality. These notions constitute independent semantic domains but are comparable in terms of semantic structure and scope. The argumentation is accompanied by examples retrieved from an electronic corpus which are representative of the formal diversity Galician offers for the expression of these semantic categories.

\section{Keywords}

semantics, grammar, modality, evidentiality, Galician

\section{Contents}

1. Introduction. 2. Modalities: from logic to linguistics. 2.1. Traditional classes of modality. 2.2. Other views on the organization of modal categories. 2.2.1 Dynamic and deontic modality beyond the traditional view. 2.2.2. Alternative divisions of the modal domain. 2.3. The definition(s) of modality. 3. Modality from a typological perspective. 4. Modalities without modality: an alternative framework. 5. The expression of modalities in Galician. 6. Conclusion. 


\section{Introdución}

Ta lingüística galega, o termo modalidade designa, cando menos, dúas nocións:

(i) os diferentes tipos de oracións (declarativo, interrogativo, imperativo, exclamativo) e as forzas ilocutivas expresadas por eles ("modalidades da oración") e (ii) os dominios semánticos tradicionalmente cońecidos como modalidade dinámica, modalidade deóntica e modalidade epistémica. O presente traballo interésase exclusivamente por esta segunda noción.

A modalidade é un tema que, desde antigo, fascinou as persoas interesadas pola filosofía, a lóxica e a lingüística. Nas últimas décadas, a lingüística xerou innúmeros traballos sobre a modalidade desde as máis diversas perspectivas e, na actualidade, a modalidade constitúe unha área de estudo central nos plans de traballo de moitos e relevantes grupos de investigación. Con todo, a modalidade nunca deixou de ser un terreo esvaradío e de consistencia variable. O seu estudo teórico caracterízase por unha continua revisión da súa definición e divisións e as súas aplicacións prácticas pola busca permanente de novas descricións e análises.

Durante o último medio século, a lingüística galega estivo inmersa nun proceso de construción permanente marcado por catro preocupacións principais (Álvarez 2019: 99-106): (i) a prioridade da lingua oral no traballo de campo e na descrición lingüística, (ii) o estudo da tradición escrita e a elaboración de recursos a partir dela, (iii) o desenvolvemento da variedade estándar e (iv) a difusión dos resultados da investigación en diferentes frontes. Neste panorama, en que os estudos gramaticais quedan excluídos das principais prioridades da incipiente lingüística galega, enténdese que a tradición gramatical adquira a xeografía dun "río de curso curto e sinuoso" (Cidrás \& Dubert-García 2017). Neste río, os estudos sobre modalidade contribúen cunha parte moi reducida do caudal.

Os traballos de lingüística galega que centran a súa atención na modalidade ou nalgún tipo de unidade modal son poucos. As contribucións de García Represas $(1995,2000,2001)$ destacan por asumir un enfoque onomasiolóxico, da función á forma, e, así, parten de conceptos como a dúbida, a certeza, a necesidade ou a obriga para explorar a súa expresión lingüística en galego. Outros traballos ocúpanse de pezas lingüísticas particulares, como os auxiliares modais (Montero Küpper 1999) ou o verbo cumprir (Loureiro-Porto 2013), estes dous últimos cun carácter contrastivo galego-alemán e galego-inglés, respectivamente. Tamén debemos contar aquí o artigo de Rodríguez-Espiñeira (2019), que, aínda que centrado no calco español da expresión galega se cadra, trata inevitablemente a forma galega e constitúe o primeiro traballo en dedicarlle unha atención considerable a este marcador epistémico. Non se pode deixar de mencionar os traballos que se ocupan dos adverbios disque e seica (Rosales Sequeiros 2000; Sousa 2012; Cidrás 2016), formas asociadas coa evidencialidade e, polo tanto, moi próximas ao ámbito modal. Nas principais gramáticas da lingua 
(Álvarez \& Xove 2002; Freixeiro Mato 2006a; Freixeiro Mato 2006b), rastréxanse referencias á modalidade no tratamento das diversas categorías formais en que se organizan estas obras, principalmente nas perífrases e o modo verbais e no adverbio, así como nos marcadores textuais. Todos estes traballos constitúen contribucións relevantes para o coñecemento das expresións modais do galego. Con todo, faltan estudos que se interesen pola discusión arredor da problemática noción de modalidade e que procuren fornecer marcos para integrar as formas particulares nunha visión de conxunto dos recursos de modalización que posúe o sistema lingüístico. Existe unha tendencia a dedicar unha maior atención a certas unidades que expresan modalidade que á modalidade en si e isto non é unha particularidade da lingüística galega, senón unha característica da lingüística a nivel xeral.

Dous obxectivos guían o desenvolvemento desta contribución. O primeiro deles é atopar unha caracterización coherente e operativa da modalidade e os seus tipos. Nunha área de estudo que se deixou levar excesivamente polas características formais das linguas máis estudadas (latín e grego nun primeiro momento, inglés e outras linguas europeas máis recentemente), cómpre asumir unha definición estrita dos dominios conceptuais e unha perspectiva ampla da súa manifestación lingüística. O segundo obxectivo consiste en ilustrar os principais mecanismos con que conta a lingua galega para a expresión das diferentes categorías modais mediante exemplos de corpus. Ademais, o traballo abriga a esperanza de estimular o debate sobre unha área pouco atendida nos estudos de lingüística galega.

O artigo comeza cunha presentación das categorías modais tal e como foron concibidas tradicionalmente na lingüística e dos principais intentos de definir a noción de modalidade $(\$ 2)$. Pasa despois $(\$ 3)$ a analizar os recursos formais de que as linguas do mundo se serven para a expresión dos diferentes tipos de modalidade. Partindo do anterior, desenvólvese, na seguinte sección (\$4), unha crítica das perspectivas máis influentes sobre a modalidade para propoñer un achegamento alternativo que supere as súas eivas. A seguir $(\$ 5)$, faise unha aplicación da proposta ao galego, procurando definir e identificar as categorías modais e ilustralas mediante exemplos de corpus, antes de dar paso á conclusión $(\$ 6)$.

\section{A(s) modalidade(s): da lóxica á lingüística}

Durante a maior parte da súa historia, a modalidade foi unha noción circunscrita ao ámbito da lóxica. No seu tratamento, relativamente recente, no marco da lingüística, aínda se poden adivińar trazos que revelan este pasado. Estas pegadas son moi evidentes en manuais de semántica, disciplina cun pé na investigación filosófica, como os de Leech (1970), Lyons (1977), Kearns (2011) e García Murga (2014), ou en monografías sobre a modalidade como a de Portner (2009). Estas obras asumen 
os presupostos da lóxica proposicional e posúen un marcado carácter formal, o cal se manifesta nun interese por asuntos como as condicións de verdade dunha proposición modalizada, a intercambiabilidade dos operadores modais mediante a negación ou a caracterización formal dos contrafácticos. $\mathrm{O}$ enfoque formal da semántica tamén toma da lóxica o modelo dos mundos posibles e a tendencia a limitar a análise aos auxiliares modais ou expresións equivalentes, explicadas á luz das nocións discretas de posibilidade e necesidade.

Esta influencia da lóxica sobre a lingüística apréciase tamén en traballos máis afastados da filosofía, como os de Palmer (1979, 1986), quen recońece a importancia do filósofo von Wright (1951) á hora de determinar os tipos de modalidade. De maneira máis ou menos explícita, as ideas da lóxica sobre a modalidade están presentes na maioría de traballos lingüísticos sobre o tema, o cal pode resultar problemático na medida en que predispón os tratamentos gramaticais a operar con criterios que lles son alleos. Neste sentido, o influxo da lóxica determinou un hábito fortemente enraizado no traballo lingüístico sobre a modalidade: a atención case exclusiva aos verbos auxiliares modais (en galego, deber (de) e poder, principalmente).

Tanto a definición da modalidade como a clasificación dos seus tipos comportan numerosas dificultades e desacordos. As caracterizacións rigorosas da noción escasean. Porén, as propostas taxonómicas son case tan abundantes como os autores que estudan a modalidade. Isto revela a dificultade de concibir a modalidade como un dominio semántico básico e coherente, feito moitas veces mencionado mais raramente considerado seriamente.

A maneira de definir a modalidade limítase, en moitos casos, a listar o conxunto de nocións máis específicas incluídas baixo esta etiqueta. Existe bastante acordo no tocante aos elementos que conforman o núcleo da categoría, os cales son recońecidos pola maioría de autores. Estes subtipos de modalidade son ilustrados na primeira epígrafe desta sección $(\$ 2.1)$. As discrepancias danse, fundamentalmente, no relativo á organización do espazo modal e o status das nocións máis periféricas. Estas diferenzas de perspectiva deron lugar a unha abundancia de propostas taxonómicas, as máis relevantes das cales son presentadas na segunda epígrafe (\$2.2). A pesar das dificultades, algunhas propostas de definición da modalidade gozan de grande aceptación e serán revisadas na última epígrafe da sección (\$2.3).

\subsection{As clases tradicionais de modalidade}

Os tres tipos básicos de modalidade distinguidos na tradición lóxica son a alética (do grego alétheia 'verdade'), relativa aos modos da verdade, a deóntica (do grego déon 'obriga, deber'), relativa aos modos da obriga, e a epistémica (do grego epistéme 'coñecemento'), relativa aos modos do coñecemento (von Wright 1951: 1-4). Sen dúbida, a primeira destas tres clases foi a que recibiu máis atención no paradigma 
lóxico. Neste ámbito, os conceptos chave para a caracterización das categorías modais son a necesidade e a posibilidade. Por exemplo, para a modalidade alética, se unha proposición é verdadeira en calquera circunstancia, dirase que é necesariamente verdadeira (e.g., $O$ diámetro dun círculo debe pasar polo seu centro). Se non é necesariamente falsa, dirase que é posiblemente verdadeira (e.g., Unha persoa pode ser máis vella que seu tío). Este tipo de modalidade tamén é chamado modalidade lóxica (Carnap 1947: 173-177; von Wright 1951: 28; Kearns 2011: 79-84).

Porén, nos estudos lingüísticos, o uso da noción de modalidade alética é escaso. Palmer (1986: 11) sinala a dificultade para distinguir entre modalidade alética e modalidade epistémica cando afirma que "there is no distinction between [...] what is logically true and what the speaker believes, as a matter of fact, to be true". Non obstante, enunciados como os anteriores poden ser modalizados epistemicamente (e.g., Probablemente, o diámetro dun círculo debe pasar polo seu centro), o cal apunta a unha maior proximidade da modalidade alética cos tipos non-epistémicos de modalidade, que tamén poden caer baixo o alcance da modalidade epistémica. A modalidade alética é raramente empregada en lingüística porque os enunciados que a expresan son infrecuentes (Narrog 2012: 7) e porque, seguramente, pode ser asimilada a algún subtipo de modalidade non-epistémica, como a dinámica (vid. \$2.2.1).

$\mathrm{Na}$ literatura lingüística, as clases tradicionais de modalidade son a dinámica, a deóntica e a epistémica (Nuyts 2006: 2-6). Todas elas foran xa propostas no marco da lóxica modal por von Wright (1951), quen outorga ás dúas últimas un lugar parello ao da modalidade alética. A modalidade dinámica é mencionada por von Wright (1951: 28), mais só nunha breve nota. As seguintes series de exemplos ilustran, respectivamente, as modalidades dinámica, deóntica e epistémica mediante os auxiliares modais deber (de) e poder.

(1a) Esa rapaza pode nadar dez quilómetros seguidos.

(1b) Debo saír de aquí canto antes.

(2a) Xa podes marchar.

(2b) O neno debía volver antes das 11 .

(3a) A inacción do goberno puido causar esta desfeita.

(3b) A acusada debe de estar ocultándolles información.

Modalidade dinámica. A modalidade dinámica atribúe ao primeiro participante dun estado de cousas $(\mathrm{EdC})^{1}$ unha capacidade ou habilidade (1a) ou unha necesidade (1b). Palmer (2001: 76-79) distingue dous tipos de posibilidade dinámica — de habilidade (abilitive) e volitiva-, correspondentes aos auxiliares do inglés can e will. A necesidade dinámica é expresada mediante o modal must, aínda que, segundo o

1. Un estado de cousas é o contido designado por unha predicación, isto é, a estrutura semántica correspondente a algún tipo de suceso do mundo. 
autor, estes casos son raros (cf. Palmer 1990: 113-132). Van der Auwera \& Plungian (1998), pola súa parte, distinguen entre modalidade interna ao participante, que correspondería á lectura que tipicamente se fai de (1), e modalidade externa ao participante. Esta última é representada en exemplos como os de (4), onde son as circunstancias externas, no canto das propiedades internas do participante, as que que fan o EdC posible ou necesario.

(4a) Agora que despexaron o curso do río, pode nadar dez quilómetros seguidos.

(4b) Para chegar a tempo á competición de natación, debo saír de aquí canto antes.

Modalidade deóntica. A modalidade deóntica defínese tradicionalmente en termos de permiso (2a) e obriga (2b), entendidos como unha indicación da posibilidade ou da necesidade da situación descrita no enunciado en relación cun código moral. Esta definición aparentemente clara e estrita agocha certa diversidade interna. Neste sentido, Palmer (2001: 70-72) afirma que o tipo máis común de deónticos é o dos directivos, que constitúen unha clase de actos de fala, o das ordes, cuxa finalidade é conseguir que o interlocutor leve a cabo unha determinada acción. Desde esta perspectiva, (2a) pode ser interpretado como un deóntico directivo, pero (2b) non. Ademais, Palmer (2001: 72-73) distingue outro tipo de deónticos que chama comisivos, vinculados a actos de fala en que o emisor adquire un compromiso. Con esta etiqueta, Palmer (2001: 72) cobre usos do auxiliar do inglés shall, como John shall have the book tomorrow ou You shall do as you are told.

Modalidade epistémica. A modalidade epistémica adoita definirse ben como unha avaliación das probabilidades de que unha situación chegue a se realizar, ben como a expresión do compromiso de quen fala coa información dada (e en moitas ocasións como ambas á vez). As principais distincións danse en termos de posibilidade (3a) e necesidade (3b), neste caso en referencia ao cońecemento que se posúe acerca do mundo. Para Coates (1983: 18-20), os verbos auxiliares con valor epistémico do inglés poden relacionarse cunha suposición (must, should e ought) ou cunha avaliación de posibilidades (will, may, might e could). O primeiro grupo constitúe o tipo inferencial e o segundo o tipo non-inferencial. Estas dúas clases dispóńense nunha escala cuxos extremos son a confianza (must; will) e a dúbida (should, ought; may, might, could). Palmer (2001: 24-31), pola súa banda, distingue tres tipos de modalidade epistémica: especulativa, dedutiva e presuntiva (assumptive no orixinal). Como noutras ocasións, o autor dá cobertura con estas distincións aos usos dos auxiliares modais do inglés, neste caso may, must e will, respectivamente. Curiosamente, Palmer (2001: 25) indica que "there seem to be few languages that have a system with all three markers, but English is an exception", o cal é boa mostra do papel que xoga a lingua inglesa na confección das clases modais. 
No tratamento da modalidade epistémica, adoita poñerse en xogo a noción de inferencia ou dedución e asumirse que esta se manifesta mediante o auxiliar must ou o seu equivalente noutras linguas, como deber (de) en galego. A relación entre as formas inferenciais e a modalidade epistémica é problemática, como se verá máis adiante.

\subsection{Outras propostas de organización da modalidade}

A taxonomía modal bosquexada en $\$ 2.1$ foi a que tivo máis éxito e difusión nos traballos lingüísticos mais non é, nin moito menos, a única. $\mathrm{O}$ status modal das tres clases principais é rara vez discutido. Porén, a natureza exacta dos elementos que deben ser incluídos baixo as etiquetas dinámica e deóntica coñece certa controversia (\$2.2.1). Ademais, existe bastante diversidade de propostas no tocante ao status relativo das tres categorías tradicionais $(\$ 2.2 .2)$.

\subsubsection{Modalidades dinámica e deóntica alén do tradicional}

As variantes interna e externa da modalidade dinámica gozan de ampla aceptación. Xunto a estas, Nuyts $(2005,2016)$ propón unha terceira clase, que chama modalidade dinámica circunstancial e a que o propio autor lle recońece un status controvertido. Esta variante incluiría "possibilities/potentials and necessities/inevitabilities [...], but then not related to any participant in the state of affairs in particular, but inherent in the state of affairs described in the clause as a whole" (Nuyts 2016: 35). Unha diferenza fundamental entre a modalidade dinámica circunstancial e a externa (“imposta ao participante", nos termos de Nuyts 2016) é, precisamente, o rol xogado polo primeiro argumento: a necesidade ou posibilidade é relativa a este participante (aínda que non interna a el) só no caso da modalidade externa ${ }^{2}$. O autor ilustra esta noción con exemplos como os seguintes ${ }^{3}$ :

(5a) All ships can sink.

(5b) Little Stevie cannot have broken the vase since he was not around.

(5c) John has to be the murderer, there was nobody else in the house.

(5d) It is possible to open the door now, I've cleaned up the rubbish behind it.

(Nuyts 2005: 8; Nuyts 2016: 35)

2. Con todo, van der Auwera \& Plungian (1998: 80) parecen deixar a porta aberta a incluír os valores da modalidade dinámica circunstancial de Nuyts $(2005,2016)$ na súa modalidade externa, pois esta "refers to circumstances that are external to the participant, if any, engaged in the state of affairs [destaque meu]".

3. Como sinala un(ha) revisor(a), nos exemplos (5b) e (5c) unha lectura inferencial resulta máis natural. 
Estes casos recordan á modalidade alética, na medida en que o tipo de modalidade que expresan ten que ver coas condicións lóxicas que conducen á posibilidade ou necesidade do EdC descrito. Con todo, non cońezo propostas que relacionen explicitamente a modalidade alética coa modalidade dinámica (circunstancial), para alén da nota de von Wright (1951:28).

A constitución interna da modalidade deóntica tamén foi obxecto de revisións. Nuyts, Byloo \& Diepeveen (2010) argumentan en prol dunha definición alternativa á tradicional, considerando a modalidade deóntica unha categoría escalar integrada, estritamente, por graos de aceptabilidade e necesidade morais. Isto exclúe os directivos tal e como os entende Palmer (2001), mais non só. Nuyts, Byloo \& Diepeveen (2010) entenden os directivos como instrucións que informan sobre o que é posible ou necesario que o primeiro argumento faga, é dicir, como indicacións de obriga e permiso. Estes autores, polo tanto, incluirían os exemplos de (2) na clase dos directivos e non na dos deónticos ${ }^{4}$. Si recoñecerían, porén, como integrantes desta clase usos dos verbos auxiliares como (6) e casos que son xeralmente excluídos no tratamento da modalidade deóntica como os de (7), onde a aceptabilidade moral é expresada mediante recursos léxicos.

(6a) O salario dos políticos non pode depender do parlamento.

(6b) O debate sobre a eutanasia debe abrirse nesta década.

(7a) Cómpre non deixarse levar pola desesperación nos momentos difíciles.

(7b) O seu comportamento na escola é totalmente deplorable.

(7c) Aplaudimos a decisión da directiva.

No seu traballo sobre os adxectivos deónticos do inglés, Van linden \& Verstraete (2011) asumen unha caracterización gradual como a de Nuyts, Byloo \& Diepeveen (2010) e tamén separan o significado directivo do déontico, mais restrinxen este último por medio da noción de factualidade (vid. \$2.3). Deste xeito, exclúen o que consideran casos de avaliación non-modal, como os dous últimos de (7), onde o EdC é factual.

4. Repárese en que os directivos así entendidos non corresponden unicamente con actos de fala do tipo das ordes, senón que tamén inclúen a súa descrición (o asunto da performatividade será abordado en $\$ 4$ e $\$ 5$ ). Unha das conclusións a que chegan Nuyts, Byloo \& Diepeveen (2010) é que existe unha división de traballo entre os auxiliares modais e o modo imperativo en que, tipicamente, os primeiros se encargan de describir o significado directivo e os segundos de performalo. (2a) sería un directivo performativo, pois expresa un acto de fala do tipo orde, mentres que (2b) sería un directivo descritivo, xa que describe unha orde mais non constitúe un acto de fala deste tipo. 


\subsubsection{Divisións alternativas do espazo modal}

Unha división moi común do espazo modal opón a modalidade epistémica ao resto de clases modais, que constituirían a modalidade radical ou raíz (root modality) ou modalidade non-epistémica. O común é incluír baixo esta etiqueta tanto os significados dinámicos como os deónticos, moitas veces sen facer distinción explícita entre eles (e.g., Coates 1983; Declerck 2011).

De forma semellante, Palmer (2001) distingue dous sistemas modais: modalidade proposicional e modalidade eventiva. O primeiro deles comprende a modalidade epistémica e a modalidade evidencial, relacionadas ambas as dúas coa actitude da falante cara á veracidade ou o status factual da proposición (Palmer 2001: 24). O segundo sistema inclúe as modalidades dinámica e deóntica, referidas a eventos non actualizados ou potenciais (Palmer 2001: 70).

Bybee, Perkins \& Pagliuca (1994) segmentan o ámbito modal en catro categorías. A primeira delas é a modalidade orientada ao axente, a cal "reports the existence of internal and external conditions on an agent with respect to the completion of the action expressed in the main predicate" (Bybee, Perkins \& Pagliuca 1994: 177). Esta clase incluiría nocións semánticas específicas como obriga, necesidade, habilidade, desexo, que dá lugar a significados de intención e disposición (willingness no orixinal), e posibilidade radical, resultado da xeneralización da noción de habilidade. Esta modalidade orientada ao axente corresponde en boa medida á modalidade dinámica tal e como a entende Palmer (2001) (significados de volición, habilidade e necesidade) e tamén inclúe os elementos tradicionalmente considerados deónticos. Con todo, estes últimos, referidos a obriga e permiso, cando constitúen actos de fala directivos conforman a modalidade orientada ao falante, que representa a segunda das categorías propostas por Bybee, Perkins \& Pagliuca (1994). Esta área modal divídese en seis clases: imperativo, prohibitivo, optativo, hortativo, admonitivo e permisivo. A terceira categoría é a relativamente pouco controvertida modalidade epistémica. Esta indica o grao de compromiso da falante a respecto da veracidade da proposición e ten como categorías máis comunmente expresadas a posibilidade, a probabilidade e a certeza inferida. Por último, os modos da subordinación (subordinating moods no orixinal) refírense ao uso das formas empregadas para as modalidades epistémica e orientada ao falante en contextos de subordinación como a complementación, as oracións concesivas e as finais.

Van der Auwera \& Plungian (1998) aplican o termo modalidade a aqueles dominios semánticos que se poden definir en termos da oposición posibilidade/ necesidade. Isto resulta en catro categorías, a primeira das cales é a modalidade interna ao participante. Esta implica, pola parte da posibilidade, a habilidade ou capacidade do participante e, pola parte da necesidade, unha necesidade interna do participante, significados correspondentes aos exemplos da serie (1). O segundo dominio analizable en termos da mencionada oposición é a modalidade externa ao participante, ilustrada 
na serie (4). A terceira categoría distinguida por van der Auwera \& Plungian (1998) é a modalidade deóntica, que consideran un caso especial de modalidade externa ao participante. O seu uso do termo é bastante estándar, pois inclúe tanto usos directivos como non directivos. O cuarto tipo de modalidade é a epistémica, a cal é definida como un xuízo da falante sobre unha proposición, que se cualifica como incerta (posible) ou probable (necesaria). Esta dimensión inclúe a área da evidencialidade inferida. Por último, os autores indican que a única maneira coherente de agrupar as clases identificadas é xuntar as modalidades interna e externa ao participante, que conformarían a modalidade non-epistémica, e opoñelas á modalidade epistémica. Este agrupamento resulta adecuado, segundo os autores, porque as modalidades relativas ao participante atanguen aspectos internos ao EdC expresado na proposición, mentres que a epistémica ten alcance sobre a proposición no seu conxunto.

Como se pode deducir do repaso anterior, son numerosos os traballos que asumen a distinción entre modalidade radical ou non-epistémica e modalidade epistémica. Desde o punto de vista histórico, a modalidade non-epistémica é radical no sentido en que constitúe a orixe da modalidade epistémica (van der Auwera \& Plungian 1998; Narrog 2005a; Traugott 2006). Ademais, como apuntan van der Auwera \& Plungian (1998) e recońecen a maioría de autores que se ocupan da materia, existen diferenzas de alcance semántico entre a modalidade epistémica e o resto de categorías modais tradicionais. Por último, a modalidade epistémica posúe unhas posibilidades expresivas que exceden notablemente as das outras categorías modais tradicionais, confinadas á expresión mediante auxiliares verbais, adxectivos como posible e necesario e os adverbios derivados destes últimos.

Do repaso anterior extráese unha conclusión principal: as controversias na división do espazo modal concéntranse na caracterización e delimitación das áreas dinámica e deóntica, mentres que a modalidade epistémica goza en practicamente todas as propostas dun status independente e dunha definición bastante nítida. Tomando os significados tradicionais como referencia, as propostas examinadas resolven a súa clasificación principalmente trazando unha separación entre, por unha banda, as modalidades dinámica e deóntica e, por outra banda, a modalidade epistémica. Así, moitos autores agrupan os tipos non-epistémicos de modalidade nunha modalidade radical (Coates 1983) ou eventiva (Palmer 2001), distinguindo, ou non, diversos subtipos dentro desta clase.

En resumo, as divisións máis populares do espazo modal son dúas: unha tripartita (dinámica/deóntica/epistémica) e outra bipartita (epistémica/non-epistémica).

\subsection{A(s) definición(s) da modalidade}

Atopar unha definición básica, coherente e común para todas as nocións que se adoitan agrupar baixo o termo modalidade está lonxe de ser doado e, sobre todo, de 
estar libre de críticas. De feito, "[t] here is hardly any grammatical category which has been given more diverging definitions, and under the label of which a wider range of phenomena has been studied" (Narrog 2005b: 165).

Segundo Narrog (2005b), existen dúas definicións principais da modalidade nos estudos lingüísticos: (a) modalidade como expresión da subxectividade da falante, é dicir, asociada ás actitudes de quen fala e á expresión de opinións e emocións; e (b) modalidade como expresión de distincións de factualidade. Para Narrog (2005b), a caracterización (a) resulta moi vaga e non singulariza os elementos modais fronte a outros dominios semánticos. Como mostra o propio Narrog (2005b: 169-176), as actitudes da falante están presentes en todos os elementos do enunciado, desde a escolla de vocabulario ata a perspectiva desde a que se conceptualiza unha situación, o cal inclúe o aspecto, a voz, o tempo e a modalidade no sentido tradicional. Polo tanto, unha definición da modalidade como a expresión da subxectividade ou das actitudes de quen fala, sen máis detalles, carece de solidez. Con todo, a noción de actitude xoga un certo papel en propostas relevantes como as de Nuyts (2005) ou Palmer (1986, 1990).

No caso da definición (b), a modalidade asóciase co status factual dunha proposición ou dun EdC. Deste modo, unha situación modalizada é aquela que se localiza nun mundo diferente ao real e é marcada como non-factual. Narrog (2005b) ofrece a seguinte definición:

Modality is a linguistic category referring to the factual status of a state of affairs. The expression of a state of affairs is modalized if it is marked for being undetermined with respect to its factual status, i.e. is neither positively nor negatively factual. (Narrog 2005b: 184)

Este achegamento é útil para determinar que unidades son modais e cales non. Wright (1995: 156) examina usos do xerundio como You're telling me you don't love me anymore ou Estasme molestando. Segundo a autora, este uso "experiencial" da forma progresiva é non-aspectual e "focusses not on an event in time, but on the (speaking) subject's consciousness of being inside an event, state, activity, looking out". Trátase dunha mostra de subxectividade na lingua que serve para expresar as actitudes de quen fala con respecto a unha situación. Casos coma estes non son considerados exemplos de expresións modais, aínda que si manifestan a actitude da falante. Desde a perspectiva da factualidade, unha definición da modalidade en termos de actitude/ subxectividade é inadecuada porque é incapaz de discriminar exemplos coma estes. Por contra, unha definición baseada na noción de factualidade, como a que propón Narrog (2005b), descarta atinadamente este tipo de elementos, cuxa factualidade non podería ser maior.

A proposta de caracterización da modalidade do tipo (b) tivo moito éxito na lingüística en xeral, tanto na tradición formalista (e.g., Portner 2009; Kearns 2011) 
como na funcionalista (e.g., Declerck 2011; Narrog 2012). Con todo, algúns autores combinan elementos das definicións (a) e (b) nas súas propostas. Así, Palmer (2001: 8) identifica a súa modalidade proposicional coas actitudes da falante en relación coa verdade ou o status factual da proposición e a súa modalidade eventiva con situacións non factuais. Van linden \& Verstraete (2011), pola súa parte, caracterizan a modalidade deóntica en termos dunha fonte de actitude e do status factual da proposición.

\section{A modalidade desde a perspectiva tipolóxica}

A tipoloxía lingüística estuda a linguaxe a partir das propiedades (estruturais) das linguas do mundo. No caso da modalidade, o interese tipolóxico é evidente, por se tratar dun dominio funcional cunha expresión variada e, moi probablemente, presente en todas as linguas humanas (Nuyts 2005: 18-19; Boye 2012: 114-124). Seguindo a tendencia propia desta disciplina, os estudos tipolóxicos sobre a modalidade céntranse en rastrexar e analizar as súas posibilidades de expresión nas diferentes linguas. Dada a complexa natureza do dominio da modalidade, a tipoloxía lingüística dedicou unha especial atención á compartimentación do espazo modal e aos seus aspectos semánticos. É difícil facer xustiza ao conxunto de estudos tipolóxicos sobre a modalidade nos límites deste traballo, de maneira que limitarei a discusión aos datos ofrecidos por The world atlas of language structures online (WALS) (Dryer \& Haspelmath 2013), dispoñible en liña, un dos proxectos máis ambiciosos no ámbito da tipoloxía lingüística.

Os capítulos do WALS que nos interesan son tres. Ocúpanse, respectivamente, da posibilidade situacional (van der Auwera \& Ammann 2013a), da posibilidade epistémica (van der Auwera \& Ammann 2013b) e do solapamento entre os dous tipos de marcaxe modal anteriores (van der Auwera \& Ammann 2013c). A posibilidade situacional de van der Auwera \& Amman (2013a) comprende as posibilidades deóntica no sentido tradicional, circunstancial no sentido de Nuyts (2016) e aquelas relacionadas coa habilidade. Na práctica, equivale á modalidade non-epistémica ou radical. $\mathrm{O}$ antagonista da posibilidade é a necesidade e estas dúas nocións combinadas conforman o campo da modalidade nestes capítulos do WALS5 Temos, así, un concepto de modalidade moi próximo ao dos achegamentos formais e lóxicos, baseado nas ideas que o propio van der Auwera propuxera anteriormente (van der Auwera \& Plungian 1998).

5. O interese de van der Auwera \& Amman (2013a, 2013b, 2013c) pola posibilidade en detrimento da necesidade parece ter precedentes na bibliografía tipolóxica: Chung \& Timberlake (1985: 242) apuntan que "particular languages tend to be less concerned with distinguishing necessity from possibility than with distinguishing different types of possibility". 
Como todos os capítulos do WALS, os tres que nos ocupan ilustran a distribución dun determinado parámetro lingüístico entre as linguas do mundo a partir dunha mostra delas. Neste caso, o número de elementos da mostra oscila entre 200 e 240, segundo o capítulo. Todos os capítulos distinguen tres tipos de linguas. Nos dous capítulos encargados de cada tipo de modalidade (van der Auwera \& Amman 2013a; van der Auwera \& Amman 2013b), distínguense tres clases de linguas segundo a estratexia formal empregada para expresar a categoría funcional correspondente en oracións declarativas afirmativas. No caso da posibilidade situacional (mostra de 234 linguas), existen linguas que a poden expresar mediante afixos verbais (63 linguas), linguas que non contan con afixos para este fin pero si con construcións verbais, é dicir, verbos modais (158 linguas), e linguas que non contan con marcadores dos tipos anteriores, senón doutro tipo, como partículas, adverbios ou adxectivos (13 linguas). Estas últimas son infrecuentes e localízanse en puntos illados do planeta. As linguas que empregan afixos son moi comúns en Nova Guinea e América do Norte, onde é habitual a polisíntese. O tipo máis común, o que emprega construcións verbais, abunda en Europa, África e sur e sueste de Asia e é raro en Nova Guinea e Australia.

Para a posibilidade epistémica (mostra de 240 linguas), distínguense linguas que a poden expresar mediante construcións verbais (65 linguas), linguas que non contan con construcións verbais pero si con afixos (84 linguas) e linguas que só posúen outros tipos de marcadores (91 linguas). O uso de verbos modais para expresar posibilidade epistémica é un fenómeno eminentemente europeo, atestado na maioría das linguas das familias indoeuropea e urálica. Tamén é común no sur da India e en África Occidental. No resto do mundo, a súa presenza é escasa e, nas Américas, non se dá ningún caso. As linguas que empregan afixos e as que empregan outros recursos repártense a maioría do planeta, con algunhas zonas de predominancia dun dos tipos (e.g., afixos en Nova Guinea, outros recursos no centro de África).

No terceiro capítulo, van der Auwera \& Amman (2013c) examinan ata que punto as linguas do mundo posúen marcadores comúns para os dous tipos de modalidade investigados. Tamén distinguen agora tres tipos de linguas: aquelas con marcadores modais que cobren toda a área da modalidade (posibilidade e necesidade, tanto situacional como epistémica), aquelas con marcadores que cobren ben as posibilidades situacional e epistémica, ben as necesidades situacional e epistémica, e aquelas con marcadores que en ningún caso codifican simultaneamente modalidade situacional e epistémica. No primeiro caso falamos de linguas cun alto grao de solapamento (36 linguas), no segundo de linguas con certo grao de solapamento (66 linguas) e no terceiro de linguas sen solapamento (105 linguas). As primeiras son características de Europa e realmente raras fóra desta área. O predominante xeograficamente é a non existencia de solapamento na expresión dos tipos de modalidade, aínda que as linguas con certo grao de solapamento son comúns na maioría do planeta.

Van Olmen \& van der Auwera (2016: 365-373) analizan a modalidade desde a perspectiva do europeo medio estándar (Standard Average European), unha área 
lingüística ou Sprachbund que ten no seu centro as linguas xermánicas occidentais e as galorromances, pero que cobre a maioría do continente europeo. A partir dos datos do WALS, conclúen que a dobre polifuncionalidade modal, equivalente ao alto grao de solapamento de van der Auwera \& Amman (2013c), e a verbalidade da modalidade epistémica (a expresión deste tipo de modalidade mediante verbos auxiliares) son trazos eminentemente europeos, isto é, características presentes na maioría de linguas de Europa, ausentes nas linguas indoeuropeas orientais e raras nas linguas xeograficamente adxacentes e na maioría do resto das linguas do mundo.

Os datos do WALS mostran que (i) os verbos auxiliares son, a nivel tipolóxico, o mecanismo máis frecuente para expresar a modalidade non-epistémica; (ii) no caso da modalidade epistémica, a utilización de verbos modais é un trazo eminentemente europeo, aínda que tamén é frecuente noutros puntos do planeta, como o sur da India e África Occidental; (iii) a polisemia modal total ou dobre polifuncionalidade é moi rara fóra de Europa.; (iv) a existencia de auxiliares verbais modalmente polisémicos responde ás características particulares das linguas europeas e non é representativo da diversidade lingüística. Dado o lugar privilexiado que ocupan as linguas europeas na teoría lingüística, non é disparatado concluír que as súas particularidades formais sexan en boa medida responsables do problemático concepto de modalidade actualmente dominante.

\section{Modalidades sen modalidade: un marco de traballo alternativo}

As categorías incluídas baixo o paraugas da modalidade son diversas e, para unificalas, adoita empregarse algún criterio semántico. No cońecido como modelo de mundos posibles (vid. Menzel 2017), recórrese ás nocións de necesidade e posibilidade ${ }^{6}$, entendidas xeralmente como categorías discretas que conforman unha distinción binaria, especialmente nos marcos formais (e.g., Kratzer 1981), mais non só (e.g., van der Auwera \& Plungian 1998). Un problema deste enfoque é que as modalidades deóntica e epistémica comprenden máis valores que os reflectidos nesta oposición

6. Os mundos posibles refírense ás diversas formas alternativas que podería adoptar a realidade. O mundo real é unha destas opcións e, polo tanto, forma parte do conxunto de mundos posibles. Un mundo posible diferente ao mundo real constitúe un universo alternativo completo que diverxe polo menos nun punto da realidade. $\mathrm{O}$ conxunto de mundos posibles é infinito, pois infinitos son os puntos en que a realidade podería ser diverxente. Basicamente, este sistema crea un dominio onde se pode aplicar a noción de verdade a situacións non-factuais. Desta maneira, unha proposición é necesariamente verdadeira se aplica á totalidade do conxunto de mundos posibles pertinente e é posiblemente verdadeira se aplica polo menos a un deses mundos posibles. Cal é o conxunto pertinente de mundos posibles determínao o tipo de modalidade en xogo (cf. Kearns, 2011, pp. 82-85). 
binaria, isto é, cada unha delas conforma unha escala de máis de dous valores. Unha variante do modelo de mundos posibles propón recońecer o carácter escalar das categorías modais, identificando os seus valores con diferentes niveis de nonfactualidade. Este achegamento supera as dificultades da postura binaria, pero comporta o mesmo problema de fondo: a falta dunha substancia semántica común, unha definición coherente da modalidade como espazo conceptual. Neste sentido, o recurso á non-factualidade como principio unificador parece arbitrario, na medida en que separa valores que a todas luces pertencen a unha mesma área semántica: é o caso, por exemplo, da certeza, claramente un valor epistémico (unha avaliación de probabilidades) e factual (unha avaliación como $100 \%$ probable) e, por isto último e de acordo co modelo de mundos posibles e as súas variantes, non modal.

O influente modelo cognitivo da dinámica de forzas (Talmy 1988; Talmy 2000: 409-470) enfronta problemas semellantes. A dinámica de forzas proporciona unha estrutura conceptual para un conxunto de sistemas cognitivos, entre eles a linguaxe. Neste último caso, a dinámica de forzas actúa cunha función estruturadora a través de varios niveis lingüísticos, dotando de coherencia conceptual dominios non relacionados ${ }^{7}$. Así, este modelo pode ser empregado para caracterizar un amplo abano de categorías lingüísticas, de modo que non é útil para agrupar as clases modais tradicionais. De feito, a modalidade concíbese, neste marco, asociada a diversos esquemas mentais de dinámicas de forzas, mais sen se lle outorgar un concepto propio e común a todas as súas manifestacións. Ademais, se consideramos categorías modais concretas, como a modalidade epistémica, resulta difícil comprender que motivaría a redución dos seus valores a outra categoría conceptual, como a dinámica de forzas, pois os xuízos de probabilidade, neste caso, e, en xeral, as avaliacións de EdCs son ferramentas básicas na interacción dos seres humanos co mundo (Nuyts 2005: 18-19). Lampert \& Lampert (2000) levan a cabo un extenso repaso crítico da modalidade desde unha perspectiva cognitiva, prestando especial atención ao modelo de dinámica de forzas, e conclúen que "it seems in principle impossible to provide a holist characterization of Modality that would be based on a common conceptual substance. [...] as a cognitively valid category Modality is simply gratuitous [destaque meu]" (Lampert \& Lampert 2000: 296).

Se admitimos que a modalidade tal e como foi tradicionalmente entendida carece de xustificación como categoría conceptual, cabe preguntarse que propiciou o seu éxito como categoría de análise lingüística. Unha razón de peso é a existencia dunha forte tendencia entre as linguas máis estudadas a posuír unha categoría gramatical, a dos verbos auxiliares modais, que exprese todos os significados da modalidade

7. A idea central do modelo de Talmy é que a dimensión lingüística da modalidade deóntica remite a forzas sociais que comprendemos con base no noso entendemento das forzas físicas. Sweetser (1990: 56-68) estendeu o modelo de forzas á modalidade epistémica, convertendo, mediante metáfora, as forzas físicas e sociais do mundo real en forzas epistémicas relativas ao mundo mental. 
tradicional ou, cando menos, varios deles (vid. \$3). Esta conexión entre os tres valores modais tradicionais non se verifica só na polisemia dos auxiliares, senón tamén no desenvolvemento semántico destas pezas lingüísticas, que comeza nos significados dinámicos, pasa polos deónticos e chega, finalmente, aos epistémicos, tanto no plano diacrónico (Traugott 2006) como no ontoxenético (Hickmann \& Bassano 2016). Expresións non gramaticais do contido modal (e.g., verbos léxicos, adverbios, adxectivos) habitualmente carecen da polisemia dos auxiliares, non mostran a mesma evolución e suscitan un interese dificilmente comparable ao provocado polos verbos modais. Ademais, o emprego do sistema de auxiliares como principal expońente da modalidade explica que a evidencialidade e outros dominios sexan frecuentemente excluídos da nómina de categorías modais. A relevancia outorgada aos auxiliares como expresións gramaticais sen dúbida xogou un papel determinante na xestación dun concepto de modalidade escasamente coherente. Para Lampert \& Lampert (2000: 296), a única razón que xustificaría manter a categoría da modalidade sería a de fornecer un correlato semántico para a categoría formal dos verbos modais, o cal equivalería a abrazar un mandato claramente determinado por unha ideoloxía eurocéntrica.

Os inconvenientes anteriores maniféstanse na dificultade para ordenar ou delimitar o espazo modal e na proliferación de propostas de clasificación e son recońecidos, dunha maneira ou doutra, por moitos autores na literatura funcionalista:

The different notions generally subsumed under the heading "modality" do not seem to represent a single and coherent semantic category. (Hengeveld 1987: 56)

Mood and modality are not so easily defined as tense and aspect [...]. In fact, it may be impossible to come up with a succinct characterization of the notional domain of modality and the part of it that is expressed grammatically. (Bybee, Perkins \& Pagliuca 1994: 176)

[...] the phenomena which are discussed in the literature under the labels of "mood" and "modality" do not constitute a unified semantic domain which could be given a single cover-definition. (Dik 1997: 241)

Modality and its types can be defined and named in various ways. There is no one correct way. (van der Auwera \& Plungian 1998: 80)

Porén, son moi poucos os que cuestionan a conveniencia de seguir empregando o concepto de modalidade como categoría de análise lingüística, probablemente porque tal proceder requiriría propoñer alternativas e deconstruír un campo de estudo que leva décadas, se non séculos, establecido.

A proposta revisionista máis interesante e mellor artellada seguramente sexa a de Nuyts (2005), que parte da idea de que os distintos tipos de modalidade son, en realidade, nocións semánticas bastante diverxentes entre si. Seguindo a tendencia da gramática funcionalista, Nuyts (2005) sitúa as diferentes categorías modais no 
contexto do sistema de cualificacións de eventos, isto é, á par doutros mecanismos que serven para modificar, localizar e avaliar EdCs. Os distintos tipos de cualificacións considéranse cognitivamente básicos e universais e conforman unha xerarquía que se manifesta lingüisticamente no seu alcance semántico respectivo. Polo tanto, as modalidades epistémica e deóntica ou a evidencialidade deben ser estudadas de maneira autónoma, no mesmo nivel de análise que o tempo ou o aspecto. Tanto estes como aquelas son susceptibles dunha definición básica, a diferenza do que acontece co concepto de modalidade.

A modalidade é un dominio que só se pode caracterizar aludindo ás nocións semánticas concretas que engloba, o cal lle recońece un certo status, mais este deriva necesariamente do que teñen en común as categorías que inclúe. $\mathrm{O}$ ingrediente principal desta nova receita da modalidade é a noción de actitude: as cualificacións modais serven para expresar diferentes tipos de actitudes da falante en relación co EdC. Desta maneira, modalidade equivale a avaliación actitudinal, o cal elude os atrancos de empregar a noción de actitude en sentido amplo (vid. \$2.3), pois, en tanto que avaliacións (un tipo de cualificacións de EdCs), as modalidades deben axustarse a unha serie de trazos (cf. Nuyts 2017: 62-66):

- Estrutura escalar. O dominio semántico de cada modalidade está constituído por tres ou máis valores que corresponden a diferentes graos dunha mesma propiedade.

- Alto alcance semántico. As cualificacións modais operan sobre o EdC, mais tamén sobre outros operadores do $\mathrm{EdC}$ como o aspecto ou a localización temporal e espacial. Isto quere dicir que unha expresión modal non ve limitado o seu significado por, por exemplo, un marcador temporal.

- Carácter performativo ${ }^{8}$. Os marcadores modais non se limitan a describir a actitude do emisor, senón que a performan, no sentido de que constitúen un compromiso do emisor con esa actitude, é dicir, identifícano como responsable dese xuízo.

Esta redefinición da modalidade carrea unha revisión do mapa de categorías modais en, polo menos, dúas direccións. Por unha parte, a modalidade debe excluír certas categorías tipicamente consideradas modais, por non se axustaren aos criterios definitorios da modalidade, e incluír outras tipicamente non consideradas modais, por si responderen a estes criterios. $\mathrm{O}$ primeiro dos supostos ten como albo principal a modalidade dinámica, cuxos valores non conforman unha escala, senón unha oposición binaria, cuxo alcance semántico é moito menor que o (do resto) das cualificacións modais e que non ten carácter performativo, senón que está orientada

8. Téńase en conta que este uso de performativo é netamente diferente ao que se fai na influente teoría dos actos de fala (Austin 1962). 
ao primeiro argumento do EdC (vid. Nuyts 2005; Gisborne 2007)9. Na situación oposta encóntranse a modalidade afectiva ou a evidencialidade inferencial (vid. \$5), que cumpren os requisitos esixidos e deben ser incluídas na nómina de categorías modais.

Por outra parte, cómpre remodelar a estrutura interna de certas categorías a fin de acomodalas aos criterios establecidos. A evidencialidade ten valores inferenciais, que son modais no sentido proposto, e valores reportativos e experienciais, que non están orientados á falante nin conforman unha escala e, en consecuencia, non son modais ${ }^{10}$. De maneira semellante, a modalidade deóntica debe ser restrinxida a graos de aceptabilidade e necesidade morais, nas liñas suxeridas por Nuyts, Byloo \& Diepeveen (2010) ou Van linden \& Verstraete (2011), gañando así coherencia semántica e abrindo a porta ao recońecemento da diversidade formal da súa expresión.

Recoñecer que as cualificacións de EdCs poden ser agrupadas baixo unha mesma etiqueta non debe escurecer unha consecuencia fundamental deste marco alternativo: a modalidade tórnase nunha noción pouco relevante, cun status parello, por exemplo, ao dunha potencial noción de "situación" referida a cualificacións localizadoras de EdCs como o tempo e o espazo.

\section{A expresión das modalidades na lingua galega}

Nesta proposta, asumirei unha definición estrita das categorías conceptuais e unha perspectiva ampla sobre a súa realización formal. Esta maneira de proceder está xustificada polo comportamento das linguas, que adoitan combinar recursos léxicos e gramaticais no desempeño dunha mesma función. Intentarei, pois, ofrecer unha mostra dos distintos tipos de mecanismos mediante os cales se expresan as categorías modais. Como fonte de exemplos lingüísticos empregarei CORTEGAL (Álvarez de la Granja \& González Seoane 2021), un corpus en liña de acceso libre en construción que recolle textos escritos elaborados no marco do exame de Lingua e literatura galegas da ABAU (a proba de Avaliación do Bacharelato para o acceso á Universidade). Todas as composicións deste corpus están relacionadas con un de catro posibles temas: "consumo e produción", "a gastronomía", "os conflitos familiares" e "os modelos ou referentes da mocidade" (para máis detalles sobre o corpus, véxase Álvarez de la

9. É pertinente sinalar que Dik (1997: 241-242) lle outorga un status periférico á súa modalidade inherente, equivalente á dinámica, que, recoñece, menciona na discusión das categorías modais unicamente porque o desenvolvemento desta "modalidade" adoita dar lugar a marcadores máis estritamente modais.

10. A inclusión da inferencialidade entre as categorías modais e a exclusión do resto de dominios evidenciais do ámbito da modalidade non é en absoluto novidoso e ten precedentes en traballos como os de van der Auwera \& Plungian (1998), Narrog (2009: 10-11) e Nuyts (2017). 
Granja 2018). Estes textos contan coa vantaxe de posuíren un carácter argumentativo que fai que o posicionamento actitudinal de quen escribe resulte ineludible.

Os dominios funcionais susceptibles de seren considerados modalidades no sentido proposto son catro: as modalidades deóntica, epistémica, inferencial e afectiva. A seguir, ofrezo unha breve caracterización e exemplos de cada unha delas. Aproveitarei os exemplos para ilustrar o carácter escalar das categorías e, máis adiante, intentarei demostrar que todas elas teñen un alto alcance semántico. Todos os exemplos tirados de CORTEGAL corresponden a usos performativos das modalidades, aínda que, como sinalarei posteriormente, todas elas contan con recursos deícticos que permiten describir o seu contido, no canto de performalo.

Modalidade deóntica. Establece o grao de aceptabilidade moral (en sentido amplo) do EdC. Recursos típicos inclúen algúns usos dos auxiliares deber (de), ter que (8), poder (9), haber (de) e cumprir (10), mais tamén diversas construcións con adxectivos como esencial (11), ou aceptable $(12)^{11}$.

(8) A sociedade debe consumir, temos que facelo, pero temos que ter en conta que os produtos non aparecen sós, pois temos que pensar profundamente neste tema, xa que se non fóra pola produción, non seríamos ninguén. (CORT_0796, CORTEGAL)

(9) A gastronomía moderna pode resultar saborosa, pero, debido á sua escaseza no prato, non consegue enchernos. Entón, pode abrirse o debate de se a cociña é ou non é arte, dado que a cociña que é considerada arte (a gastronomía moderna) ten moi pouca duración nos nosos paladares [...] (CORT_0242, CORTEGAL)

(10) Como último consello cómpre sabermos cociñar xa que é básico nas nosas vidas. (CORT_0466, CORTEGAL)

(11) O consumismo é un dos maiores problemas desta sociedade e é esencial educar aos nosos pequenos para que eviten esta situación, dándolle un bo exemplo e abrindo a porta á posibilidade dun mundo mellor. (CORT_0055, CORTEGAL)

(12) O mundo globalizado de hoxe en día fai que conseguir a receta de calquera prato sexa moi fácil polo que é habitual ver estas modas. Na maioría dos casos non chegan a modificar a tradición rexional, pero moi de cando en vez pode ocorrer, cousa que é perfectamente aceptable. (CORT_0532, CORTEGAL)

11. Nos exemplos, as expresións relevantes están destacadas mediante cursiva. Simplifiquei certos aspectos da transcrición dos textos, como os riscados, por non seren relevantes para os propósitos deste traballo. 
Os valores deónticos móvense nunha escala que vai da necesidade á inaceptabilidade morais, pasando pola aceptabilidade moral. A necesidade é expresada a través de diferentes recursos: auxiliares verbais en (8), un verbo léxico en (10) e un predicado adxectivo en (11); mentres que en (9) e (12) temos aceptabilidade expresada por medio dun auxiliar verbal e dun predicado adxectivo, repectivamente. Non hai exemplos de inaceptabilidade moral nos casos anteriores, mais esta poder ser expresada mediante adxectivos como inaceptable, inadmisible, lamentable e reprobable e verbos como condenar e reprobar.

Modalidade epistémica. Determina o grao de probabilidade do EdC. Inclúense aquí algúns usos do auxiliar poder (13), os verbos cognitivos crer (14), pensar e coidar, adxectivos como certo, seguro, probable (15), e posible e adverbios como seguramente, probablemente, posiblemente, quizais (16), talvez e se cadra. Curiosamente, no único caso de seica en CORTEGAL (17), este adverbio é usado con valor de posibilidade epistémica, isto é, como sinónimo de quizais ${ }^{12}$.

(13) [...] é normal que se desenvolva o sector gastronómico nunha sociedade consumista que ve no sector a oportunidade de abrir un novo mercado aberto a innovacións e a un público moi grande necesitado de novas sensacións e experiencias. Na miña opinión é unha moda que pode afianzarse na sociedade debido a que o sector da hostelería e a restauración é necesario na nosa sociedade, ten recursos, tanto tecnolóxicos como económicos, e o máis importante, un público moi grande. (CORT_0673, CORTEGAL)

(14) Creo que a causa principal deste fenómeno é a publicidade que acadou este tipo de cocińa grazas aos xa mencionados programas e concursos televisivos. (CORT_0768, CORTEGAL)

(15) A algunhas persoas pareceralles raro pero, si unha persoa non viaxa, é moi pouco probable que tome comida á que non está acostumada [...]. (CORT_0074, CORTEGAL)

(16) Persoalmente creo que si que se trata dunha moda pasaxeira que quizáis a xente acepte polo simple feito de que "se leva agora". (CORT_0627, CORTEGAL)

(17) Así pois, aínda que sabemos que unha leituga do mercado ou calquer outro vexetal é máis sano, máis ecolóxico e máis natural, compramos a leituga do Eroski que é máis grande e sobre todo mais barata e así, cos cartos que

12. Seica é un adverbio que se desenvolveu a partir da cadea en sintaxe libre (eu) sei que (Cidrás 2016). Ao seu significado orixinal de inferencia a partir de percepción sensorial hai que sumar na actualidade o valor de evidencia reportada, análogo ao de disque. Usos como os de (17) son innovadores mais non insólitos e mostran a deriva de seica cara á posibilidade epistémica, fenómeno cuxas causas conviría esclarecer. 
aforramos, mercamos un novo móbil, outro coche e, seica, se nos atopamos nunha época de "BOOM" inmobiliario nos metemos nunha hipoteca dun piso adquirido mediante un préstamo que non seremos capaces de devolver. (CORT_0524, CORTEGAL)

O espazo semántico da modalidade epistémica está conformado por valores que se moven entre os extremos da certeza e a imposibilidade e pasan polo punto intermedio da posibilidade. Esta última é expresada mediante o auxiliar poder en (13) e mediante o adverbio quizais en (16). Os extremos non están representados nos exemplos, pero cońecen expresión mediante adxectivos como certo e seguro e o adverbio certamente, pola parte positiva, e mediante o adxectivo imposible, pola parte negativa. Unha parte importante dos valores epistémicos e dos recursos que os expresan corresponden ás áreas que median entre a posibilidade e cada un dos extremos, que podemos chamar probabilidade e improbabilidade, segundo o tipo de polaridade que posúa a cualificación ${ }^{13}$. Expresan probabilidade o verbo crer en (14) e o adxectivo probable en (15). Especialmente rica é a expresión adverbial desta área semántica, onde posiblemente, probablemente e seguramente expresan graos crecentes de probabilidade, como recońecen Álvarez \& Xove (2002: 627-628). Como no caso da modalidade deóntica, o lado negativo da escala é defectivo (non posúe expresión mediante auxiliares e adverbios ou esta é moi restrinxida) e exprésase principalmente a través do adxectivo improbable, alén do xa mencionado imposible, e do verbo dubidar.

Modalidade inferencial. Expresa o grao de fiabilidade do proceso inferencial que xustifica a existencia do EdC. Formas comúns en galego para expresar esta modalidade son os auxiliares deber (de) (18), haber (de) (19), e ter que. Tampouco son raros adverbios como obviamente, claramente, evidentemente e os seus correspondentes adxectivos (20), aparentemente (21), e o verbo parecer (22), e verbos cognitivos como supoñer (23), sospeitar ou imaxinar.

(18) A todos nos gusta comer e quedar fartos por iso cando vemos un plato de comida nun libro ou pantalla entranos a fame e pensamos "que bo debe de estar iso". (CORT_0728, CORTEGAL)

(19) Nos nenos e adolescentes este factor é determinante, xa que ninguén plantéxase o feo que pode ser algo, ou o caras que son moitas cousas, porque se todo o mundo o ten... ha de ser bo. (CORT_0417, CORTEGAL)

(20) Moitas veces, influídos pola sociedade consumista e polos anuncios que atopamos en calquer lugar (televisión, radio, prensa, incluso nas propias rúas) soemos mercar cousas máis caras só porque as coñecemos ou ben

13. Repárese en que certeza e imposibilidade non deixan de ser valores da (im)probabilidade, correspondentes a un grao do $100 \%$. 
mercar cousas que realmente non nos son necesarias. $E$ evidente, polo tanto, que vivir rodeados de publicidade afecta ao noso modelo de vida actual. (CORT_0747, CORTEGAL)

(21) No texto, Carmela (aparentemente con un nivel económico alto) decide ir a protestar polo baixo prezo do leite das súas vacas. (CORT_0733, CORTEGAL)

(22) Cada vez é maior o número de persoas que queren aprender a cociñar simplemente polo gusto pola comida. A este grupo hai que engadir os efectos que ten o auxe do deporte, xa que moita xente quere aprender a cociñar dunha maneira equilibrada e sabendo o que come. Este incremento como actividade de ocio non parece estar freándose. Todo o contrario. (CORT_0781, CORTEGAL)

(23) Con isto refírome a que á xente cando viaxa (ou non necesariamente cando viaxe), gústalle coñecer cousas doutras culturas; os seus costumes, as súas vestimentas, a súa lingua e tamén a súa gastronomía. Eu supoño que isto, no caso concreto de descubrir variedades na gastronomía, crea na xente unha afición polas comidas exóticas e, nalgúns casos, as leva a querer dedicarse a unha profesión coma a gastronomía. (CORT_0353, CORTEGAL)

A modalidade inferencial posúe unha estrutura semántica en certa medida análoga á das dúas modalidades anteriores. Os recursos arriba exemplificados, coa excepción de (22), corresponden á porción positiva da escala e codifican graos altos de fiabilidade, (20), graos medios, (18) e (21), e graos baixos, (19) e (23). A parte negativa da escala é especialmente defectiva no caso da modalidade inferencial, pois non está claro que existan mecanismos que codifiquen especificamente os valores correspondentes. Con todo, é posible expresar inferencialidade negativa recorrendo á sintaxe, combinando marcas de negación verbal (principalmente, mais non só, o adverbio non) cunha parte dos mecanismos anteriores, nomeadamente aqueles de natureza verbal, como os auxiliares, ou que requiren apoio verbal, como os predicados adxectivos. Unha ilustración disto témola en (22), onde parecer é precedido por non. A orde dos elementos é aquí relevante, pois a posición preverbal da marca negativa sinala o seu alcance sobre a modalidade expresada polo verbo, mentres que a posición posverbal (isto é, preverbal a respecto de estar) marcaría o alcance da modalidade sobre a negación. Noutras palabras, non debe confundirse a expresión dunha cualificación modal negativa (non parece que se estea freando) coa cualificación modal dun EdC negativo (parece que non se está freando).

Onde a modalidade inferencial difire das demais é na súa falta dun punto intermedio, correspondente a unha consideración neutra nos termos impostos pola dimensión modal. No caso da modalidade epistémica, o punto neutral é a posibilidade, que indica que o EdC é compatible cos cońecementos do emisor. De maneira similar, a formulación dun xuízo deóntico en termos de aceptabilidade implica que o emisor 
non ve como necesario ou condenable o EdC. A modalidade inferencial carece desta zona neutral, dado que se refire á fiabilidade dun proceso que permite xustificar ou rexeitar a existencia do EdC.

A delimitación entre as modalidades inferencial e epistémica é un asunto espiñento. Trátase de áreas nitidamente separadas no terreo conceptual, mais conectadas desde o punto de vista lóxico, pois implican un proceso de razoamento a partir de evidencias orientado a avaliar o status factual dun $\mathrm{EdC}^{14}$. A separación das dúas categorías radica en que cada unha delas se refire a unha parte diferente dun mesmo proceso cognitivo (Cornillie 2009: 57-59; Nuyts 2017: 72-73). A modalidade epistémica codifica o resultado dese proceso, en termos de graos de probabilidade. Si que implica, ás veces de maneira moi forte, que existe evidencia para levar a cabo o xuízo, mais non apunta cara a estas probas de maneira directa. A modalidade inferencial, pola súa parte, fai referencia ao propio proceso de razoamento e outórgalle un grao de fiabilidade, pero non codifica a probabilidade de que teña lugar o EdC. Con certeza, cando un falante expresa, por exemplo, alta fiabilidade da inferencia dun EdC é fácil entender que tamén ve como altamente probable a súa existencia. Non obstante, non se pode perder de vista que estamos ante dúas categorías conceptuais separadas que denotan aspectos diferentes dun mesmo proceso de razoamento.

Modalidade afectiva. Indica o grao de (des)gusto a respecto do EdC. O seu escaso recońecemento como categoría modal seguramente ten que ver co feito de non cońecer a expresión mediante recursos gramaticais como os verbos auxiliares. Ademais, trátase dunha área dificilmente vinculable aos valores tradicionais de posibilidade e necesidade. Algúns recursos comúns en galego para a expresión desta categoría son os adverbios e locucións adverbiais afortunadamente (24), por sorte (25), lamentablemente (26), por desgraza (27), e ben (28), ou verbos como gustar, encantar ou aborrecer.

(24) O lóxico é pensar que a importancia que acadaron a cocińa e mais a gastronomía sexa duradeira, pois supón unha clara mellora na nosa calidade de vida. Non obstante, hai razóns para pensar que é unha moda pasaxeira e é que afortunadamente a comida é un ben ao que poden acceder a maioría do noso país; (CORT_0477, CORTEGAL)

(25) Por sorte, esta etapa "do pavo", non dura moito más lonxe que os 18 anos [...]. (CORT_0978, CORTEGAL)

14. A posibilidade epistémica constitúe unha excepción, na medida en que non implica, no plano puramente semántico, a existencia de tal proceso, senón simplemente que o emisor carece de argumentos que neguen a existencia do EdC. Con todo, o común é que os xuízos en termos de posibilidade epistémica posúan algún tipo de apoio xustificativo —-(13) é iluminador neste sentido- e rara vez sexan verdadeiras declaracións de ignorancia (vid. Przyjemski 2017: 187-190). 
(26) A producción en exceso coma hai agora non é algo necesario, pero, lamentablemente estamos nunha economía na que temos que consumir en exceso para que a produción non se deteña e haxa despidos, peche de empresas... (CORT_0788, CORTEGAL)

(27) Por desgracia outros países están en moi peores condicións nas que non teñen nin as necesidades básicas como ocorre en Venezuela. (CORT_0518, CORTEGAL)

(28) En conclusión, vexo moi claro porque a cociña é un dos puntos fortes na actualidade. Está ben que se descubran tantos tipos de receitas, porque de esta forma o noso estómago nunca se aburrirá da comida. (CORT_0008, CORTEGAL)

A modalidade afectiva ten a mesma estrutura semántica que as modalidades deóntica e epistémica. Posúe unha porción positiva, representada en (24), (25) e (28), e unha porción negativa, exemplificada en (26) e (27). Nestas, pode darse un alto grao de refinamento na gradación: por exemplo, a que se conseguiría con $\{$ ben/moi ben/xenial\}, que expresarían, nun contexto como (28), graos crecentes de aprecio cara ao EdC. Esta modalidade tamén conta cun punto intermedio, neutral en termos afectivos, correspondente á indiferenza, cuxa expresión máis representativa probablemente sexa o predicado complexo dar igual.

A relación entre a modalidade afectiva e a deóntica é análoga á que existe entre a epistémica e a inferencial: a aprobación ou condena morais poden implicar aprecio e desprezo, respectivamente, no plano afectivo e viceversa. Con todo, apreciar, desprezar ou sentir indiferenza cara a un EdC non é o mesmo que consideralo desexable, aceptable ou inaceptable desde o punto de vista moral ${ }^{15}$.

Pasemos agora a tratar o alcance semántico. As modalidades forman parte dun sistema de categorías lingüísticas que cualifican, isto é, modifican, localizan ou avalían, EdCs. Postular este tipo de sistema é común en modelos lingüísticos funcionalistas, como a Gramática Funcional (Dik 1997: 217-245) ou a Gramática de Papel e Referencia (van Valin \& LaPolla 1997: 25-52). Estes modelos asumen que a variación interlingüística no ámbito das categorías cualificadoras de EdCs agocha padróns universais referidos ao modo en que estas categorías se relacionan entre si e cos EdCs e as súas partes, propiedade cońecida como alcance ou escopo

15. Dada a proximidade semántica entre as modalidades afectiva e deóntica, non é estraño que certos recursos sexan susceptibles dunha ou outra lectura dependendo do contexto. $\mathrm{O}$ adverbio ben é un bo exemplo disto. Un(ha) revisor(a) ofrece os seguintes exemplos: Non está ben que o cura diga esas palabras (modalidade deóntica); Está ben que botemos unha peza (modalidade afectiva). De maneira semellante, neste traballo, lamentable inclúese como expresión deóntica e lamentablemente como expresión afectiva, por considerar que tipicamente eses son os seus valores respectivos, pero isto podería variar en determinados contextos. O panorama complícase aínda máis se engadimos a polisemia de adxectivos deónticos como esencial (vid. Van linden \& Verstraete 2011: 151) e epistémicos como posible, que poden ter lecturas en termos de modalidade dinámica. 
(scope en inglés). Deste xeito, as cualificacións de EdCs ordénanse, nestes modelos, en xerarquías que reflicten o alcance relativo dos distintos tipos de cualificacións.

O reflexo máis directo da estruturación interna das categorías cualificadoras atopámolo nas posibilidades de interpretación que nos brinda a súa combinación nun mesmo enunciado. Limitareime a ilustrar as relacións entre, por unha parte, as modalidades e, por outra, as categorías localizadoras (tomando como referencia o tempo) e as categorías modificadoras (cuxa referencia será o aspecto interno), sen entrar nas relacións que se dan dentro de cada un destes niveis (por exemplo, o alcance relativo da localización temporal e a espacial). Sirvan de ilustración os seguintes exemplos (destaco en cursiva a expresión de maior alcance e en grosa aquela cuxo alcance é menor).

(29) O goberno debe reducir o gasto en defensa o ano que vén. [modalidade deóntica e tempo]

(30) Probablemente mañá chova. [modalidade epistémica e tempo]

(31) Parece que onte non veu. [modalidade inferencial e tempo]

(32) É xenial que teu tío chegase o mes pasado. [modalidade afectiva e tempo]

(33) Seguramente deixou de traballar pola mañá. [tempo e aspecto interno]

No exemplo (29), deber expresa unha necesidade moral que non se ve limitada pola expresión temporal $o$ ano que vén: a desexabilidade de que o goberno reduza o seu gasto en defensa no ano próximo é unha actitude do emisor desde o momento da enunciación de (29) e non comeza nun punto do futuro, como sería o caso se o marcador temporal tivese alcance sobre a expresión modal. Da mesma maneira, o xuízo epistémico expresado en (30) por medio de probablemente é válido desde o momento en que se pronuncia e non a partir do día seguinte. $\mathrm{O}$ mesmo é certo, mutatis mutandis, para a cualificación inferencial de (31), mediante a cal o emisor comunica que infire o EdC desde o momento da enunciación e non o día anterior. (32) corresponde a un EdC localizado no mes anterior ao momento da enunciación, sobre o cal o emisor expresa, no momento de falar, a súa alegría. Por último, a perífrase aspectual de (33) vese limitada polo marcador temporal, na medida en que a finalización do EdC, sinalada pola perífrase, ten lugar no marco que establece a expresión temporal pola mañá. Ademais, as dúas expresións, xunto co resto da predicación, son obxecto da avaliación epistémica expresada mediante seguramente. En conclusión, as modalidades teñen alcance sobre as cualificacións localizadoras de EdCs e estas, á súa vez, teñen alcance sobre as cualificacións modificadoras e, en ningún dos casos, ao contrario.

Os exemplos da serie anterior, de igual maneira que o resto de exemplos desta sección, son ilustracións do carácter performativo das modalidades. A performatividade determina o maior alcance destas cualificacións, ao vinculalas á falante no momento da enunciación: por definición, os usos performativos das modalidades non poden 
caer baixo a influencia de cualificacións localizadoras ou modificadoras porque expresan o punto de vista do falante no momento presente, no canto de contribuír a detallar o EdC. Porén, a expresión das modalidades posúe recursos que permiten suspender o carácter performativo do contido modal. Mecanismos deícticos como a flexión verbal serven para atribuír o xuízo modal a entidades diferentes do emisor no momento da enunciación:

(34) Condenei o seu comportamento ata que coñecín as súas circunstancias persoais.

(35) Daquela non parecía probable que Trump fose chegar á Casa Branca.

(36) O veciño deixou de sospeitar que agachamos algo.

(37) Alegrareime moito de que veñas á cea.

Nestes exemplos, os mecanismos modais atribúen o contido modal non ao emisor, senón a outras entidades, sexa o falante nalgún momento diferente do presente, sexa unha entidade distinta do falante. Estes usos dos marcadores modais non expresan cualificacións modais, senón que constitúen EdCs por si mesmos. Proba disto é que poden ser modificados e localizados, é dicir, caer baixo o alcance de categorías como o aspecto interno e a localización temporal (cuxos marcadores aparecen en cursiva nos exemplos para sinalar o seu maior alcance): é o que acontece coas expresións temporais en (34) e (35) e a aspectual en (36).

Esta proposta para o estudo das categorías modais está lonxe de ser exhaustiva, tanto no número de recursos formais que trata como nos factores relevantes que discute. Así, un dos retos máis interesantes que unha proposta deste tipo debe afrontar é a explicación da existencia dunha gran variedade formal destinada á expresión do mesmo significado. Por que, por exemplo, para a expresión da probabilidade epistémica contamos co adxectivo probable, o adverbio probablemente e o verbo crer, entre outros recursos? Todo apunta a que estamos ante formas que constitúen un paradigma, isto é, alternativas formais cuxa escolla vén determinada por factores diferentes do significado común a todas elas. Esta vía xa foi explorada para a modalidade epistémica (Nuyts 2001), mais só en linguas xermánicas, que necesariamente diverxerán do galego, mentres que para o resto de categorías modais non existen achegamentos comparables.

\section{Conclusión}

A visión tradicional da modalidade responde ás características estruturais das linguas europeas e carece de coherencia semántica e validez cognitiva. A lingüística galega ofrece un terreo practicamente virxe no referido aos estudos sobre modalidade, o 
cal regala a oportunidade de superar os atrancos que presentan outras tradicións de coñecemento. Esta contribución tentou dar un primeiro paso nesta dirección propoñendo unha maneira alternativa de achegarse aos significados e marcadores modais. Nesta proposta, a modalidade e as súas divisións, tal e como se entenderon tradicionalmente, son reorganizadas para obter categorías semánticas cuxa caracterización non presenta problemas. Identificáronse catro destas categorías, as cales gardan semellanzas entre si pero constitúen dominios lingüísticos merecentes de atención individual. Estas novas modalidades posúen unha gran variedade de recursos expresivos que fará do seu estudo un estimulante desafío.

\section{Financiamento}

Este traballo recibiu apoio financeiro da Xunta de Galicia e do Fondo Social Europeo a través das axudas de apoio á etapa predoutoral nas universidades do Sistema universitario galego (referencia ED481A-2017/23) e foi elaborado no marco do proxecto Corpus de textos gallegos escritos por estudiantes en el ámbito académico. Herramienta para el análisis de la competencia escrita en lengua gallega financiado por FEDER/Ministerio de Ciencia, Innovación y Universidades - Agencia Estatal de Investigación (referencia PGC2018-096069-B-100).

\section{Agradecementos}

Agradezo os comentarios que sobre unha versión previa deste artigo realizaron Maruxa Álvarez, Francisco Cidrás e dúas persoas anónimas. 


\section{Referencias bibliográficas}

Álvarez de la Granja, María. 2018. Corpus de textos de estudantes galegos (CORTEGAL). Aspectos metodolóxicos. En Marta Díaz, Gael Vaamonde, Ana Varela, M. ${ }^{a}$ Carmen Cabeza, José M. García-Miguel \& Fernando Ramallo (eds.), Actas do XIII Congreso Internacional de Lingüistica Xeral, 55-62. Vigo: Universidade de Vigo. http://cilx2018.uvigo.gal/actas/resumos/655842.html [04/03/2021].

Álvarez de la Granja, María \& Ernesto González Seoane (eds.). 2021. Corpus de textos galegos escritos por estudantes no ámbito académico. Santiago de Compostela: Instituto da Lingua Galega. http:// ilg.usc.gal/cortegal [15/01/2021].

Álvarez, Rosario. 2019. Galician linguistics: between Hispanic philological tradition and visibility in the Luso-Brazilian sphere. En Gabriel Rei-Doval \& Fernando Tejedo-Herrero (eds.), Lusophone, Galician, and Hispanic linguistics: bridging frames and traditions, 92-112. London: Routledge.

Álvarez, Rosario \& Xosé Xove. 2002. Gramática da lingua galega. Vigo: Galaxia.

Austin, J. L. 1962. How to do things with words. Oxford: Oxford University Press.

Boye, Kasper. 2012. Epistemic meaning: a crosslinguistic and functional-cognitive study. Berlin: De Gruyter Mouton. https://doi.org/10.1515/9783110219036

Bybee, Joan, Revere Perkins \& William Pagliuca. 1994. The evolution of grammar: tense, aspect, and modality in the languages of the world. Chicago: University of Chicago Press.

Carnap, Rudolph. 1947. Meaning and necessity: a study in semantics and modal logic. Chicago: University of Chicago Press.

Chung, Sandra \& Alan Timberlake. 1985. Tense, aspect, mood. En Timothy Shopen (ed.), Language typology and syntactic description: grammatical categories and the lexicon, vol. 3, 202-258. Cambridge: Cambridge University Press.

Cidrás, Francisco. 2016. Why do they say 'I know' when they mean 'I really don't know'? Semantic change and constructionalization of Galician particle seica. [Manuscrito inédito].

Cidrás, Francisco \& Francisco Dubert-García. 2017. A gramática galega, un río de curso curto e sinuoso. Panorama histórico dos estudios gramaticais sobre o galego. Labor Histórico 3(1). 111-125. https://doi.org/10.24206/lh.v3i1.17110

Coates, Jennifer. 1983. The semantics of the modal auxiliaries. London: Croom Helm.

Cornillie, Bert. 2009. Evidentiality and epistemic modality: on the close relationship between two different categories. Functions of Language 16(1). 44-62. https://doi.org/10.1075/fol.16.1.04cor

Declerck, Renaat. 2011. The definition of modality. En Adeline Patard \& Frank Brisard (eds.), Cognitive approaches to tense, aspect and epistemic modality, 21-44. Amsterdam: John Benjamins. https://doi.org/10.1075/hcp.29.05dec

Dik, Simon C. 1997. The theory of Functional Grammar. Part 1: the structure of the clause. 2. ${ }^{a}$ edn. Berlin: Mouton de Gruyter. https://doi.org/10.1515/9783110218367

Dryer, Matthew S. \& Martin Haspelmath (eds.). 2013. The world atlas of language structures online. Leipzig: Max Planck Institute for Evolutionary Anthropology. http://wals.info/ [15/01/2021]

Freixeiro Mato, Xosé Ramón. 2006a. Gramática da lingua galega: morfosintaxe. 2. ${ }^{\mathrm{a}}$ edn. Vol. 2. Vigo: A Nosa Terra. 
Freixeiro Mato, Xosé Ramón. 2006b. Gramática da lingua galega: gramática do texto. 2.a edn. Vol. 4. Vigo: A Nosa Terra.

García Murga, Fernando. 2014. Semántica. Madrid: Síntesis.

García Represas, Delio. 1995. As marcas de certeza na interrogación polarizada en galego. Cadernos de Lingua 12. 53-72. http://publicacionsperiodicas.academia.gal/index.php/Cadernos/article/ view/520/534 [15/01/2021].

García Represas, Delio. 2000. L'expression du doute en galicien. En Annick Englebert, Marie Pierrard, Laurance Rosier \& Dan van Raemdonck (eds.), Actes du XXIIe Congrès International de Linguistique et de Philologie Romanes (Bruxelles, 23-29 juillet 1998), vol. 7, 269-276. Tübingen: Max Niemeyer.

García Represas, Delio. 2001. A necesidade e maila obriga en galego. Cadernos de Lingua 23. 89-116. http://publicacionsperiodicas.academia.gal/index.php/Cadernos/article/view/93/105 [15/01/2021].

Gisborne, Nikolas. 2007. Dynamic modality. SKASE Journal of Theoretical Linguistics 4(2). 44-61. http://www.skase.sk/Volumes/JTL09/ [15/01/2021].

Hengeveld, Kees. 1987. Clause structure and modality in Functional Grammar. En Johan van der Auwera \& Louis Goossens (eds.), Ins and outs of the predication, 53-66. Dordrecht: Foris. http:// hdl.handle.net/11245/1.427201 [15/01/2021].

Hickmann, Maya \& Dominique Bassano. 2016. Modality and mood in first language acquisition. En Jan Nuyts \& Johan van der Auwera (eds.), The Oxford handbook of modality and mood, 430-447. Oxford: Oxford University Press. https://doi.org/10.1093/oxfordhb/9780199591435.013.20

Kearns, Kate. 2011. Semantics. 2. a edn. New York: Palgrave Macmillan.

Kratzer, Angelika. 1981. The notional category of modality. En Hans-Jürgen Eikmeyer \& Hannes Rieser (eds.), Words, worlds, and contexts: new approaches in word semantics, 38-74. Berlin: Walter de Gruyter. https://doi.org/10.1515/9783110842524-004

Lampert, Günther \& Martina Lampert. 2000. The conceptual structure(s) of modality: essences and ideologies. Frankfurt am Main: Peter Lang.

Leech, Geoffrey. 1970. Towards a semantic description of English. Bloomington, IN: Inidiana University Press.

Loureiro-Porto, Lucía. 2013. Modal necessity and impersonality in English and Galician. En Juana I. Marín-Arrese, Marta Carretero, Jorge Arús Hita \& Johan van der Auwera (eds.), English modality: core, periphery and evidentiality, 171-200. Berlin: De Gruyter Mouton. https://doi. org/10.1515/9783110286328.171

Lyons, John. 1977. Semantics. Vol. 2. Cambridge: Cambridge University Press. https://doi. org/10.1017/CBO9780511620614

Menzel, Christopher. 2017. Possible worlds. En Edward N. Zalta (ed.), Stanford encyclopedia of Philosophy. Stanford: Stanford University Press. https://plato.stanford.edu/archives/win2017/entries/ possible-worlds/ [26/04/2021]

Montero Küpper, Silvia. 1999. A categoría da modalidade en alemán e galego. En Dieter Kremer (ed.), Actas do V Congreso Internacional de Estudios Galegos, vol. 1, 727-737. Trier: Centro de Documentación de Galicia da Universidade de Trier. 
Narrog, Heiko. 2005a. Modality, mood, and change of modal meanings: a new perspective. Cognitive Linguistics 16(4). 677-731. https://doi.org/10.1515/cogl.2005.16.4.677

Narrog, Heiko. 2005b. On defining modality again. Language Sciences 27(2). 165-192. https://doi. org/10.1016/j.langsci.2003.11.007

Narrog, Heiko. 2009. Modality in Japanese: the layered structure of the clause and hierarchies of functional categories. Amsterdam: John Benjamins. https://doi.org/10.1075/slcs.109

Narrog, Heiko. 2012. Modality, subjectivity, and semantic change: a cross-linguistic perspective. Oxford: Oxford University Press. https://doi.org/10.1093/acprof:oso/9780199694372.001.0001

Nuyts, Jan. 2001. Epistemic modality, language, and conceptualization: a cognitive-pragmatic perspective. Amsterdam: John Benjamins. https://doi.org/10.1075/hcp.5

Nuyts, Jan. 2005. The modal confusion: on terminology and the concepts behind it. En Alex Klinge \& Henrik Høeg Müller (eds.), Modality: studies in form and function, 5-38. London: Equinox. https://doi.org/10.1558/equinox.29060

Nuyts, Jan. 2006. Modality: overview and linguistic issues. En William Frawley (ed.), The expression of modality, 1-26. Berlin: Mouton de Gruyter. https://doi.org/10.1515/9783110197570.1

Nuyts, Jan. 2016. Analyses of the modal meanings. En Jan Nuyts \& Johan van der Auwera (eds.), The Oxford handbook of modality and mood, 31-49. Oxford: Oxford University Press. https://doi. org/10.1093/oxfordhb/9780199591435.013.1

Nuyts, Jan. 2017. Evidentiality reconsidered. En Juana Isabel Marín Arrese, Gerda Haßler \& Marta Carretero (eds.), Evidentiality revisited: cognitive grammar, functional and discourse-pragmatic perspectives, 57-83. Amsterdam: John Benjamins. https://doi.org/10.1075/pbns.271.03nuy

Nuyts, Jan, Pieter Byloo \& Janneke Diepeveen. 2010. On deontic modality, directivity, and mood: the case of Dutch mogen and moeten. Journal of Pragmatics 42(1). 16-34. https://doi.org/10.1016/j. pragma.2009.05.012

Palmer, F. R. 1979. Modality and the English modals. London: Longman.

Palmer, F. R. 1986. Mood and modality. Cambridge: Cambridge University Press.

Palmer, F. R. 1990. Modality and the English modals. 2. a edn. London: Longman.

Palmer, F. R. 2001. Mood and modality. 2. ${ }^{\text {a }}$ edn. Cambridge: Cambridge University Press. https://doi. org/10.1017/CBO9781139167178

Portner, Paul. 2009. Modality. Oxford: Oxford University Press.

Przyjemski, Katrina. 2017. Strong epistemic possibility and evidentiality. Topoi 36(1). 183-195. https://doi.org/10.1007/s11245-015-9352-1

Rodríguez-Espiñeira, María José. 2019. La expresión epistémica si cuadra en español de Galicia. Estudos de Lingüistica Galega 11. 197-231. https://doi.org/10.15304/elg.11.5343

Rosales Sequeiros, Xosé. 2000. Uso interpretativo de la lengua: disque y seica en lengua gallega. En Francisco J. Ruiz de Mendoza Ibáńez (ed.), Panorama actual de la lingüistica aplicada, vol. 1, 375-386. Logroño: Universidad de La Rioja.

Sousa, Xulio. 2012. Estrategias evidenciales y expresión de la fuente de información en gallego: los marcadores gramaticalizados. En Xulio Viejo Fernández (ed.), Estudios sobre variación sintáctica peninsular, 75-98. Uviéu: Trabe. 
Sweetser, Eve. 1990. From etymology to pragmatics: metaphorical and cultural aspects of semantic structure. Cambridge: Cambridge University Press. https://doi.org/10.1017/CBO9780511620904

Talmy, Leonard. 1988. Force dynamics in language and cognition. Cognitive Science 12(1). 49-100. https://doi.org/10.1207/s15516709cog1201_2

Talmy, Leonard. 2000. Toward a cognitive semantics: concept structuring systems. Vol. 1. Cambridge, MA: MIT Press.

Traugott, Elizabeth Closs. 2006. Historical aspects of modality. En William Frawley (ed.), The expression of modality, 107-139. Berlin: Mouton de Gruyter. https://doi.org/10.1515/9783110197570.107

van der Auwera, Johan \& Andreas Ammann. 2013a. Situational possibility. En Matthew S. Dryer \& Martin Haspelmath (eds.), The world atlas of language structures online. Leipzig: Max Planck Institute for Evolutionary Anthropology. http://wals.info/chapter/74 [15/01/2021].

van der Auwera, Johan \& Andreas Ammann. 2013b. Epistemic possibility. En Matthew S. Dryer \& Martin Haspelmath (eds.), The world atlas of language structures online. Leipzig: Max Planck Institute for Evolutionary Anthropology. http://wals.info/chapter/75 [15/01/2021].

van der Auwera, Johan \& Andreas Ammann. 2013c. Overlap between situational and epistemic modal marking. En Matthew S Dryer \& Martin Haspelmath (eds.), The world atlas of language structures online. Leipzig: Max Planck Institute for Evolutionary Anthropology. http://wals.info/ chapter/76 [15/01/2021].

van der Auwera, Johan \& Vladimir A. Plungian. 1998. Modality's semantic map. Linguistic Typology 2(1). 79-124. https://doi.org/10.1515/lity.1998.2.1.79

Van linden, An \& Jean-Christophe Verstraete. 2011. Revisiting deontic modality and related categories: a conceptual map based on the study of English modal adjectives. Journal of Pragmatics 43(1). 150-163. https://doi.org/10.1016/j.pragma.2010.07.031

van Olmen, Daniël \& Johan van der Auwera. 2016. Modality and mood in Standard Average European. En Jan Nuyts \& Johan van der Auwera (eds.), The Oxford handbook of modality and mood, 362-384. Oxford: Oxford University Press. https://doi.org/10.1093/oxfordhb/9780199591435.013.11

van Valin, Robert D., Jr. \& Randy J. LaPolla. 1997. Syntax: structure, meaning and function. Cambridge: Cambridge University Press. https://doi.org/10.1017/CBO9781139166799

von Wright, Georg H. 1951. An essay in modal logic. Amsterdam: North-Holland.

Wright, Susan. 1995. Subjectivity and experiential syntax. En Dieter Stein \& Susan Wright (eds.), Subjectivity and subjectivisation, 151-172. Cambridge: Cambridge University Press. https://doi. org/10.1017/CBO9780511554469.008 